\title{
DMA Design of Water Distribution System Combined with Hydraulic Modelling
}

\author{
Weimin GENG ${ }^{\mathrm{a}}$, Xiaochao FU ${ }^{\mathrm{a}, 1}$, Renzheng GU ${ }^{\mathrm{a}}$ and Jun YAN \\ a Shanghai Urban Construction Vocational College, China \\ ${ }^{\mathrm{b}}$ Bentley System, Unit B505, WE international Hub, China
}

\begin{abstract}
Developing countries in Asia face challenges in reducing Non-revenue Water (NRW) and long-term effort is required for water supply companies. The strategies to address NRW mainly include increasing metering accuracy, pipeline rehabilitation, water use management etc., and District Meter Area (DMA) is one of efficient methods to control NRW. This paper describes methodology of designing DMA for water distribution network combined with hydraulic modelling in City A of South Asia. DMA design was implemented and the objection of the project is to reduce the present high levels of NRW. Firstly referring to as-built drawings, proposal for feeder mains was developed based on the Master Plan (target year 2040). Then according to the natural boundary, water supply situation, water quality etc., 19 DMAs were detailly designed. At last, a global model assembling all DMAs and feeder mains was done and applied to analyse the security of supply and check fire flow requirements. On the basis of the design work, construction of feeder mains and DMAs was carried out gradually, and metering facilities and valves were installed as required.
\end{abstract}

Keywords. DMA design, Hydraulic modelling, Water distribution system, Nonrevenue water.

\section{Introduction}

Developing countries in Asia face challenges in reducing NRW, including aging infrastructure, financial constraints, poor governance, and poor project design[1]. NRW management is a long-term process and it concerns distribution, customer service, finance and administration etc. DMA management is an efficient method to control NRW, and in recent years it has been gradually implemented in Asia. Nowadays during global water shortage, controlling water leakage not only reduces water supply costs, but also equals to open up new water sources, which has great economic significance. DMA is the partition of the water supply network into small zones, with closed valves or flowmeters installed at the boundaries. It is used for pipe network leakage management by flow measurement and analysis. Generally during DMA designing, feeder mains are firstly laid out, then DMA pipes are identified and sized considering velocity, head loss, water quality etc. Researchers made some achievements on DMA zonal methods, strength and weakness of which were analysed[2]. Enrico and Hatem[3] presented a multiobjective approach for optimizing simultaneously the installation of

${ }^{1}$ Corresponding Author, Xiaochao FU, Shanghai Urban Construction Vocational College, China.; Email: 1978582785@qq.com. 
control valves and the creation of DMAs. The application of the multiobjective optimization method sorting genetic algorithm for trading off the operational cost, excess pressure and water age etc. was introduced by Mohamad et al.[4]. Jorge et al.[5] and Liu et al.[6] respectively developed multiphase DMA design method. A novel approach was presented that a water distribution network was mapped on to a weighted undirected graph and its strength was measured by an extended modularity by a random walk strategy[7]. In some projects, pressure-reducing valves were installed in every inlet pipe and optimized to reduce leakage, and the procedure was applied to a medium-sized network[8]. Water quality is also an important question for DMA management, spatiotemporal change rules of water quality in cut-off pipelines were studied and a pilot platform was constructed by Chen et al.[9].

In this paper, methodology of designing DMAs combined with hydraulic modelling is introduced and all work follows the local guidelines. The DMAs' construction was gradually carried out and the client also supplied the NRW level which must be met.

\section{DMA design}

City A lies in the south of Asia and is the hub of commercial activities due to its large harbor. It is a densely populated and urbanized city with a land extent about $37.3 \mathrm{~km}^{2}$ and a metro population close to 700,000. The project area is part of City A and the Master Plan (target year 2040) is the base of all design work. The objection of the design is as follows.

- Proposal for feeder mains.

- Completing the models for DMAs' detail design.

- Building global model and check the security of supply and fire flow requirements.

Before and during the design, field investigation of water source, road situation, water use types etc. was conducted. All design idea conformed to 2 documents "Hydraulic Network Modelling Design Guidelines for Transmission and Distribution Mains" and "Conceptual Method Statement Review of DMA Design". The natural boundaries which are mainly rivers, lakes and railways remain unchanged as much as possible. The project area being close to the sea is characterized by gently undulating plains and low lying flat lands (see figure 1), and some slightly higher places deserve special attention. 


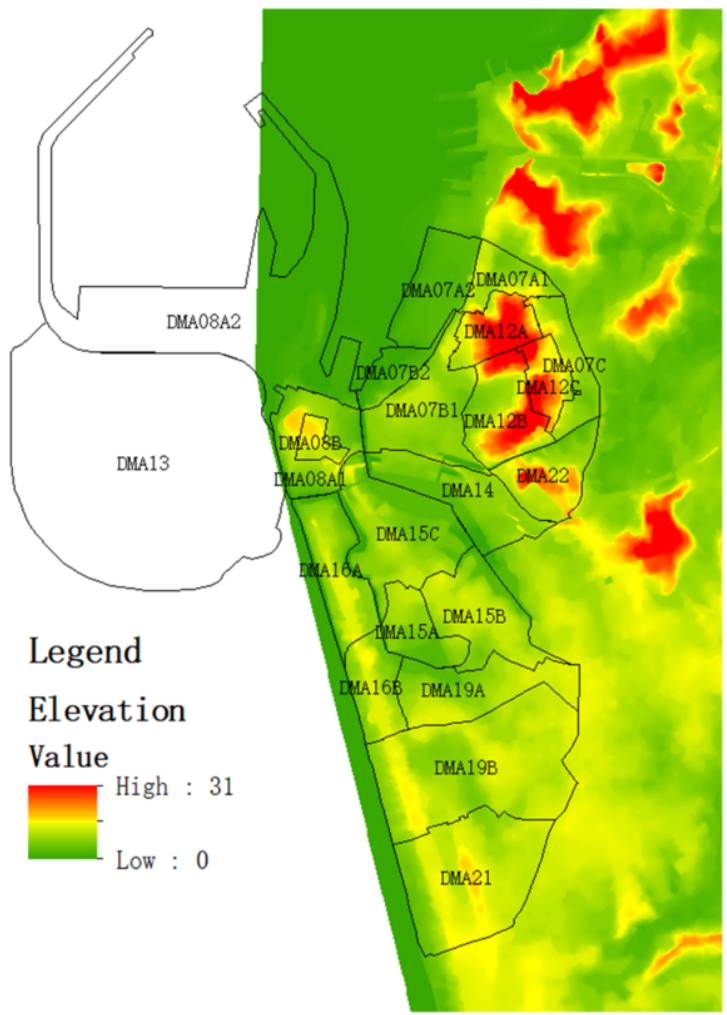

Figure 1. The elevation map of the project area.

Notes: Some area is for land reclamation, and there is temporarily no elevation data.

\subsection{Feeder Mains}

Proposals for feeder mains includes two parts: DMA boundaries' refinement and feeder mains proposals. Based on the Master Plan project of target year 2040, DMA boundaries are modified in order to meet the following rules:

- Use railways, lakes, rivers as boundaries whenever possible.

- Avoid connections between pumping and gravity zone.

- Set DMAs' boundaries in terms of elevations.

- Minimize pumping requirement.

- Design DMAs with less than 5000 connections.

- Make the best use of existing pipes.

There are 2 water supply systems: Systems E and M, which are gravity and pumping systems respectively. For some DMAs with higher elevation, the system couldn't meet the requirements of water pressure, so local pump station was adopted. In addition, because of the roles of network connectivity, ground levels, urban landscape, geographic, urban features, and field investigation, some DMAs were adjusted or separated into two or more during detailed designing such as DMA 8A. The correspondence between water supply systems and DMAs are as follows.

- $\quad$ E water supply system (gravity) supplies DMA 7A, 7B, 7C, 8A,13.

- E water supply system (local pumps) supplies DMA 12A, 12B, 12C. 
- $\quad \mathrm{M}$ water supply system (pumping) supplies DMA 8B, 14, 15A, 15B, 15C, 16A, 16B, 19A, 19B, 21, 22.

The feeder mains design was the foundation of DMAs, and the hydraulic model of 2040 peak flow was built based on historical data, the Master Plan and preliminary field investigation. There are totally 3 kinds of water demand: priority, special and residential demands. In feeder mains model, each DMA's classified sums of residential, priority and special demands were correspondingly set in each entry point. The hourly peak factors are 1.5 or 1.4 , and 1 for special demand. The main design criteria are as follows and the velocity theme map of simulation results is shown in figure 2 .

- The critical point residual pressure is set at $10 \mathrm{~m}$.

- The design range of the hydraulic gradient for new pipes is set as below. When Diameter $\geq \mathrm{DN} 300 \mathrm{~mm}$, the head loss gradient is $1.0 \sim 3.0 \mathrm{~m} / \mathrm{km}$; When Diameter $<$ DN300mm, the head loss gradient is $2.0 \sim 6.0 \mathrm{~m} / \mathrm{km}$; For gravity transmission system, maximum velocity is $3.0 \mathrm{~m} / \mathrm{s}$; For pumped transmission system, maximum velocity is $2.5 \mathrm{~m} / \mathrm{s}$.

On the feeder mains' design, some recommendations are as follows. All pipes' roughness were input according to the client's document, so we suggested that some flow and pressure measurements should be made to estimate the current main pipes' real roughness, and also the situation of existing pipes be checked. The sum peak demand of DMA 7A, 7B, 8A and 13 is about $43 \%$ of all peak demand of the project area and mainly supplied by the DN $1000 \mathrm{~mm}$ of System E (gravity supply system), so the water supply security of these DMAs is recommended to be given full consideration.

\subsection{DMAs' Detailed Design}

Detail design procedure is as follows.

- $\quad$ Sorting the existing pipelines based on shape files.

- Preliminary design of secondary mains, feeding points and boundaries.

- Simplify the entry point as a reservoir.

- Using a statistical method (Qn method) to design the diameter of small pipes (see table 1).

- Prepare the priority demand, special demand, residential demand for each DMA.

- $\quad$ Simulate the DMA model with 2040 demand and peak factor.

- Check residual pressure, velocity, and head loss gradient, and resize the pipes if necessary.

- Select the best location for the DMA meter installation, the DMA boundaries and make step arrangement of the valves. 


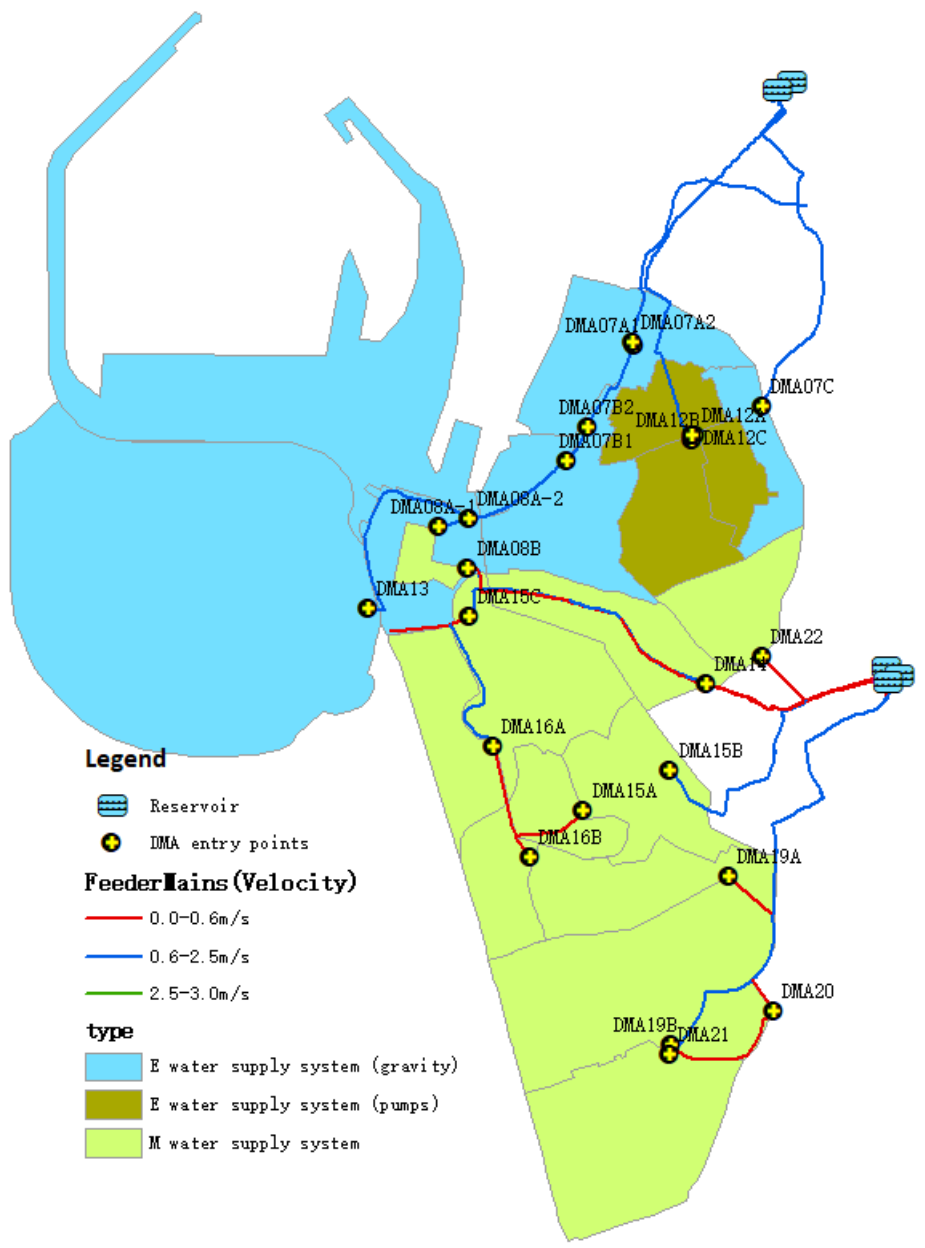

Figure 2. The velocity theme map of feeder mains model.

Table 1. Pipe sizing for smaller pipes ( $<500$ connections).

\begin{tabular}{ccc}
\hline $\begin{array}{c}\text { Number of } \\
\text { connections }\end{array}$ & $\begin{array}{c}\text { Preferred pipe } \\
\text { diameter }(\mathbf{m m})\end{array}$ & $\begin{array}{c}\text { Assumed internal } \\
\text { diameter }(\mathbf{m m})\end{array}$ \\
\hline Up to 20 & 63 & 55.6 \\
$\mathbf{2 1}$ to 85 & 90 & 79.4 \\
$\mathbf{8 6}$ to $\mathbf{1 9 0}$ & 110 & 97.1 \\
$\mathbf{1 9 1}$ to 500 & 160 & 141.2 \\
\hline
\end{tabular}

Take one DMA as an example. This DMA covers 1.14 square kilometers and provides water to about 2000 active customers. The DMA is supplied from System M by one of the existing ductile iron $400 \mathrm{~mm}$ pipe. DMA inflow meter would be installed and most of the pipes needed to be newly laid in this DMA because of the existing 
pipes' situation etc. (see figure 3). Simulation results showed that pressure, velocity and head loss gradient all met the requirements of the standard.

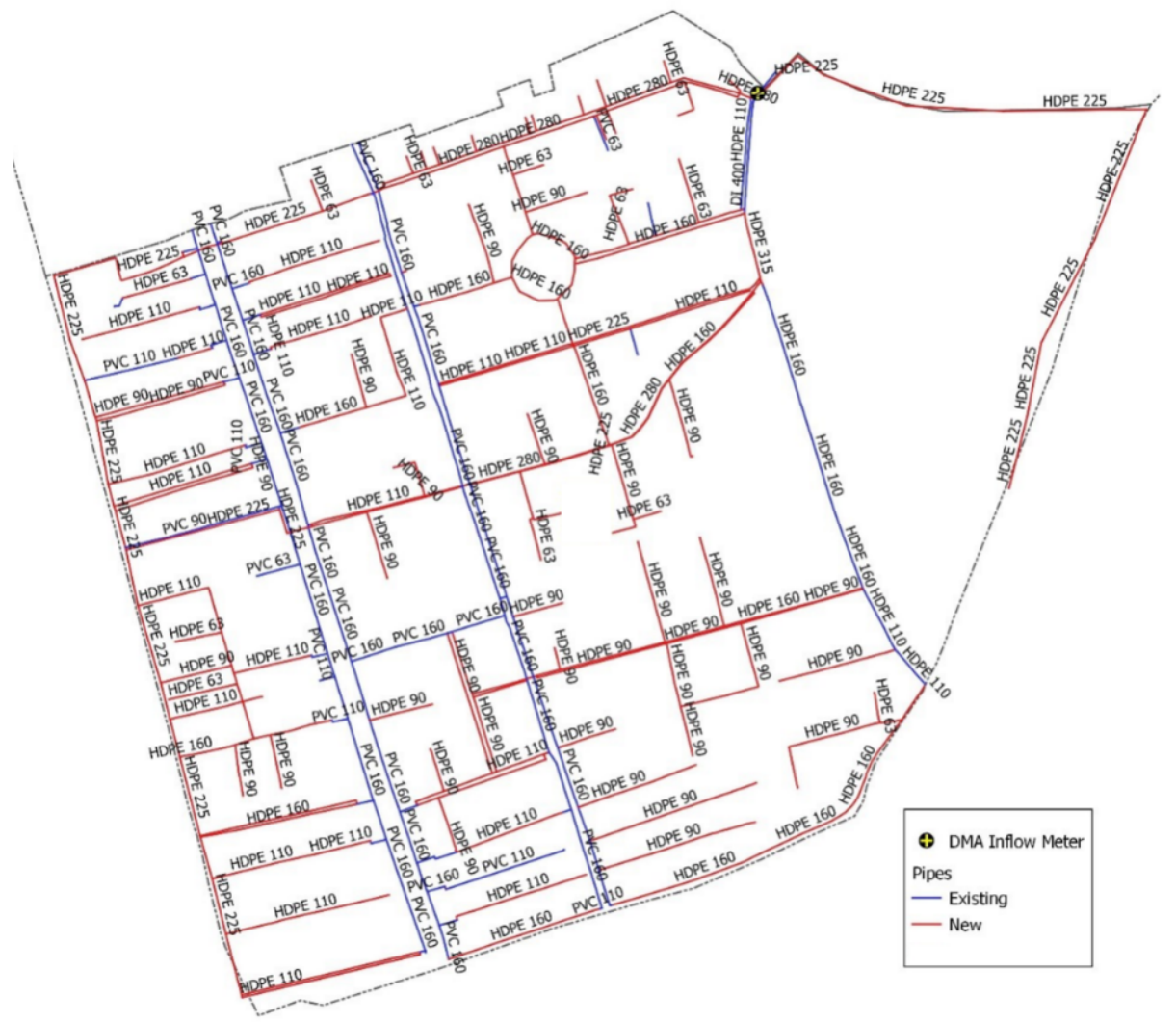

Figure 3. Pipeline layout of one DMA.

\subsection{Building Global Model}

A global model assembling all DMAs and feeder mains was done after the DMA design process (shown in figure 4), also the water source and delivery pipelines were added. The creation of the global model was necessary for the analysis of security of supply and fire flow. While designing DMAs, alternative routes were proposed but their effects couldn't be verified. The global model allowed to check the simulating results of alternative supplies and the hydraulic implications.

According to the client's design guideline, the alternative pipeline route must enable supply $50 \%$ of the maximum day demand over a period of 24 hours. It is impossible to simulate and analysis all emergency scenarios which may happen, therefore the study only focused on the worst critical scenarios which would be failure/burst on feeder mains, and these scenarios were the worst situation for each DMA. The security of supply analysis scenarios were done as follows: set burst on feeder mains upstream of the DMA inflow; open one or more boundary valves in order 
to provide enough alternative supply; simulate 24 hours and check the calculation results.

While analysing the scenarios, the alternative pipeline was adjusted as possible to reach the emergency supply. The results showed a good security of supply in all the scenarios, and the alternative pipeline route could supply over $50 \%$ of the maximum day demand over a period of 24 hours. Not all boundary valves were used in the modelling scenarios, but this didn't mean that they were unnecessary. It just meant the DMA was sufficiently supplied without opening them in case of failure on the feeder main, and these boundary valves could still be very useful locally in case the supply had to be cut for a period such as burst or repairing. Moreover, checking fire flow requirements was also implemented. The required fire flow was set $25 \mathrm{l} / \mathrm{s}$ during peak hour flow, and the minimum residual pressure at the hydrant during fire flow was $5 \mathrm{~m}$.

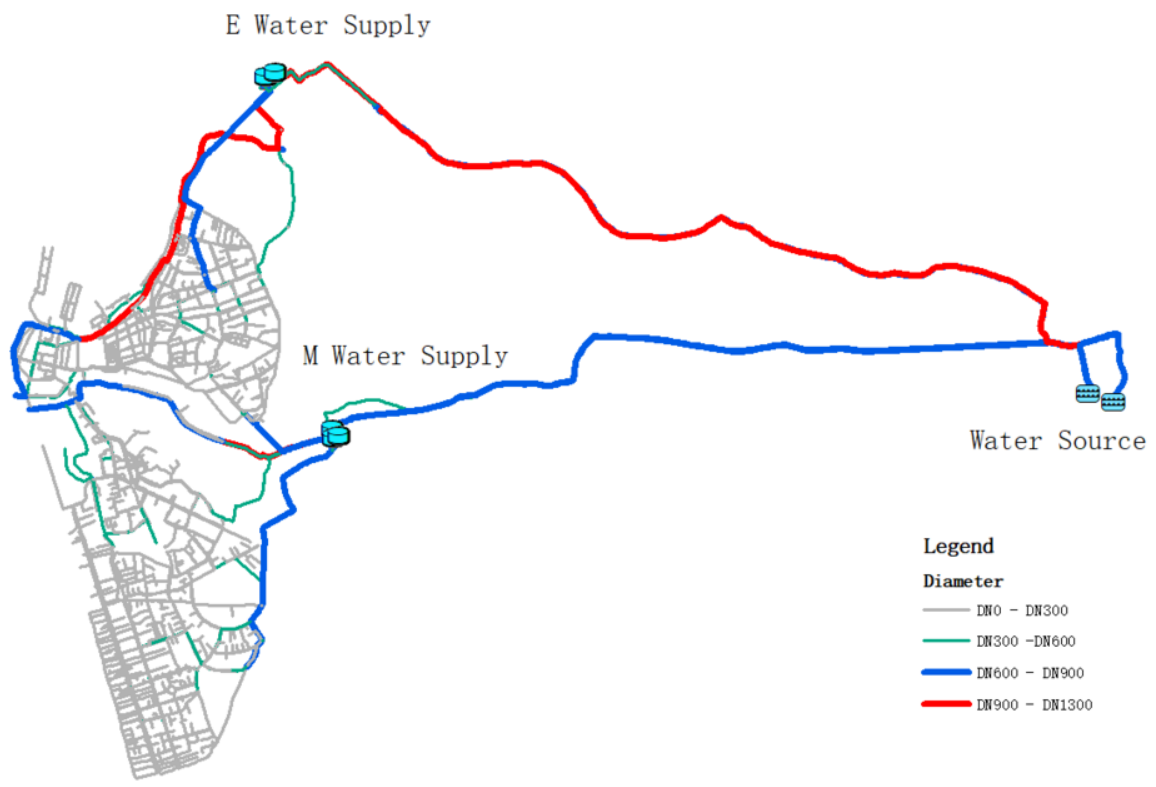

Figure 4. Global pipeline model of the project area.

Notes: The demands not in the project area were input as special nodes' demand.

\section{Conclusion}

The design was carried out for 2 years. On this design, some explanations are as follows.

- The project is based on the Master Plan project and its target year is 2040, so all design work is on the basis of 2040's demand.

- The small number of field surveys left many uncertainties as to the status of some existing pipes. During construction, the modelling was required to continuously adjust with the more investigations and excavations.

- All pipes' roughness was input according to the client's document. That some flow and pressure measurements to estimate the current main pipes' roughness were suggested. 
Based on the design work, construction of feeder mains and DMAs work was carried out gradually, and metering facilities and valves were installed as required.

\section{Acknowledgements}

This design work was supported by Shamila and Yifan Bai on site, and they collected the data for building model.

\section{References}

[1] Malcolm F., Gary W., Zainuddin B. M. G., Arie I. and Sher S. 2008 The Manager's Non- Revenue Water Handbook p3

[2] Li Bin, Zhang Guo-li, Nie Jin-xu, Jiang Hao 2018 An overview of optimized DMA zonal methods in water distribution system J. Guangdong University of Technology 35(2) 19-27

[3] Enrico C. and Hatem H. 2019 Multiobjective optimization of control valve installation and DMA creation for reducing leakage in water distribution network J. Water Resour. Plann. Manage. 145(10) 04019046 1-10

[4] Mohamad Z., Pu L. and Avi O. 2021 DMA segmentation and multiobjective optimization for trading off water age, excess pressure, and pump operational cost in water distribution systems J. Water Resour. Plann. Manage. 147(4) 04021006 1-13

[5] Jorge E. P., Emily Z. B. and G. Mahinthakumar 2019 Multiphase procedure to design district metered areas for water distribution networks J. Water Resour. Plann. Manage. 145(8) 04019031 1-10

[6] Jun Liu and Kevin E. L. 2020 Multiphase DMA design methodology based on graph theory and manyobjective optimization J. Water Resour. Plann. Manage. 146(8) 04020068 1-15

[7] Qingzhou Zhang, Zheng Yi Wu, Ming Zhao, Jingyao Qi, Yuan Huang and Hongbin Zhao 2017 Automatic partitioning of water distribution networks using multiscale community detection and multiobjective optimization J. Water Resour. Plann. Manage. 143(9) 04017057 1-14

[8] Tuqiao Zhang, Huaqi Yao, Shipeng Chu, Tingchao Yu and Yu Shao 2021 Optimized DMA partition to reduce background leakage rate in water distribution networks J. Water Resour. Plann. Manage. 147(10) 04021071 1-10

[9] Chen Da, Liu Jing-qing, Chen Huan-yu and Wang Ruo-wei 2019 Spatiotemporal change rules of water quality in cut-off water pipelines in district metering areas (DMA) Zhengjiang University (Engineering Science) [J] 53(9) 1704-10 